\title{
Bidirectional superior cavopulmonary anastomosis: how young is too young?
}

Zdenek Slavik, Robert K Lamb, Steven A Webber, Anita M Devlin, Barry R Keeton, James L Monro, Anthony P Salmon

\begin{abstract}
Objective-To define the lowest age at which the bidirectional superior cavopulmonary anastomosis can safely be used in infants with complex congenital heart defects.

Design-A retrospective analysis of clinical, echocardiographic, haemodynamic, and angiographic data in four consecutive patients undergoing bidirectional superior cavopulmonary anastomosis below the age of 2 months.
\end{abstract}

Patients-Between November 1990 and September 1993, four infants less than 8 weeks of age $(3,4,6$, and 7 weeks) underwent bidirectional superior cavopulmonary anastomosis as a primary palliation for complex heart disease. The indication for early surgical intervention was progression of cyanosis $(n=3)$ and high pulmonary blood flow causing heart failure $(n=1)$. In two infants with tricuspid atresia, surgery was performed through a right thoracotomy without the use of cardiopulmonary bypass. In one infant with double inlet left ventricle and discordant ventriculoarterial connection, cavopulmonary anastomosis was combined with an arterial switch procedure. The final infant had double inlet left ventricle with pulmonary atresia; the central pulmonary arteries were virtually discontinuous and each branch was supplied by a separate arterial duct. The central pulmonary arteries were reconstructed using the subaortic innominate vein. Temporary prostacyclin infusion was used in three patients in the immediate postoperative period.

Results-Early postoperative extubation $(5,7$, and $48 \mathrm{~h})$ was successful in three patients. The youngest child required ligation of the ductus arteriosus four days later because of severe upper body oedema. The postoperative course was complicated by prolonged effusions in two patients. All were alive and well 14-48 months postoperatively, with satisfactory systemic saturations $(80-87 \%)$ and haemodynamic indices.

Conclusions-This limited experience challenges the widely held belief that the bidirectional superior cavopulmonary anastomosis cannot be used as a primary palliation for complex heart disease in early infancy. A wider experience is required to determine the safety and indications for this approach.

(Heart 1996;75:78-82)

Keywords: bidirectional superior cavopulmonary anastomosis; congenital heart disease; infancy

Bidirectional superior cavopulmonary anastomosis (BCPA) is a well established method of treatment in children with complex congenital heart disease. ${ }^{1-5}$ Controversy remains about the safety of this procedure in neonates and small infants. ${ }^{367}$ We have therefore reviewed our initial experience with bidirectional superior cavopulmonary anastomosis in infants under the age of 8 weeks.

\section{Methods}

Between November 1990 and September 1993, four children (two male, two female) under 8 weeks of age underwent bidirectional superior cavopulmonary anastomosis as a primary surgical palliation for complex congenital heart disease. Age at operation ranged from 3 to 7 weeks and weight from 4.1 to $4.5 \mathrm{~kg}$ (table).

There were two infants with tricuspid atresia, concordant ventriculoarterial connection and pulmonary stenosis. In one of these (case
Wessex Cardiothoracic Gentre, Southamptor Hospital, Southampton Z Slavik

R K Lamb

S A Webber

A M Devlin

B R Keeton

J L Monro

A P Salmon

Correspondence to:

Dr A P Salmon, Wessex Cardiothoracic Centre, Cardiothoracic Centre,

Southampton General Hospital, Tremona Road, Southampton SO16 6YD Accepted for publication 16 August 1995
Patient data

\begin{tabular}{lllllllll}
\hline Patient & Diagnosis & $\begin{array}{l}\text { Age } \\
(\text { weeks })\end{array}$ & $\begin{array}{l}\text { Weight } \\
(\mathrm{kg})\end{array}$ & $\begin{array}{l}\text { Preop. } \\
\text { sat }(\%)\end{array}$ & $\begin{array}{l}\text { Operative } \\
\text { approach }\end{array}$ & Procedure & $\begin{array}{l}\text { Ventilation } \\
(\mathrm{h})\end{array}$ & $\begin{array}{l}\text { Hospital } \\
\text { stay }(\mathrm{d})\end{array}$ \\
\hline 1 & TAtr, PS, PDA & 3 & $4 \cdot 1$ & $60-80$ & Thoracotomy & BCPA & 288 & 38 \\
2 & TAtr, PS & 6 & $4 \cdot 5$ & 65 & Thoracotomy & BCPA & 7 & 30 \\
3 & DILV, TGA & 7 & $4 \cdot 3$ & 90 & Sternotomy & BCPA, “switch" & 5 & 18 \\
4 & DILV, TGA, & 4 & $4 \cdot 3$ & 75 & Sternotomy & $\begin{array}{l}\text { BCPA, recon- } \\
\text { struction PAs }\end{array}$ & 48 & 10
\end{tabular}

Preop sat, preoperative haemoglobin saturation; BCPA, bidirectional superior cavopulmonary anastomosis; bil, bilateral; DILV, double inlet left ventricle; PA, pulmonary artery; PS, pulmonary stenosis; TAtr, tricuspid atresia; TGA, transposition of the great arteries. 
Figure 1 Preoperative anteroposterior and lateral angiogram of case 4 ( $A$ and $B$ ) showing hypoplastic right pulmonary artery (white arrow) and bilateral arterial ducts (black arrows). Postoperatively from the superior vena cava to both lungs (C) and the use of the subaortic innominate vein to reconstruct the central pulmonary arteries is demonstrated (D). there is unobstructed flow
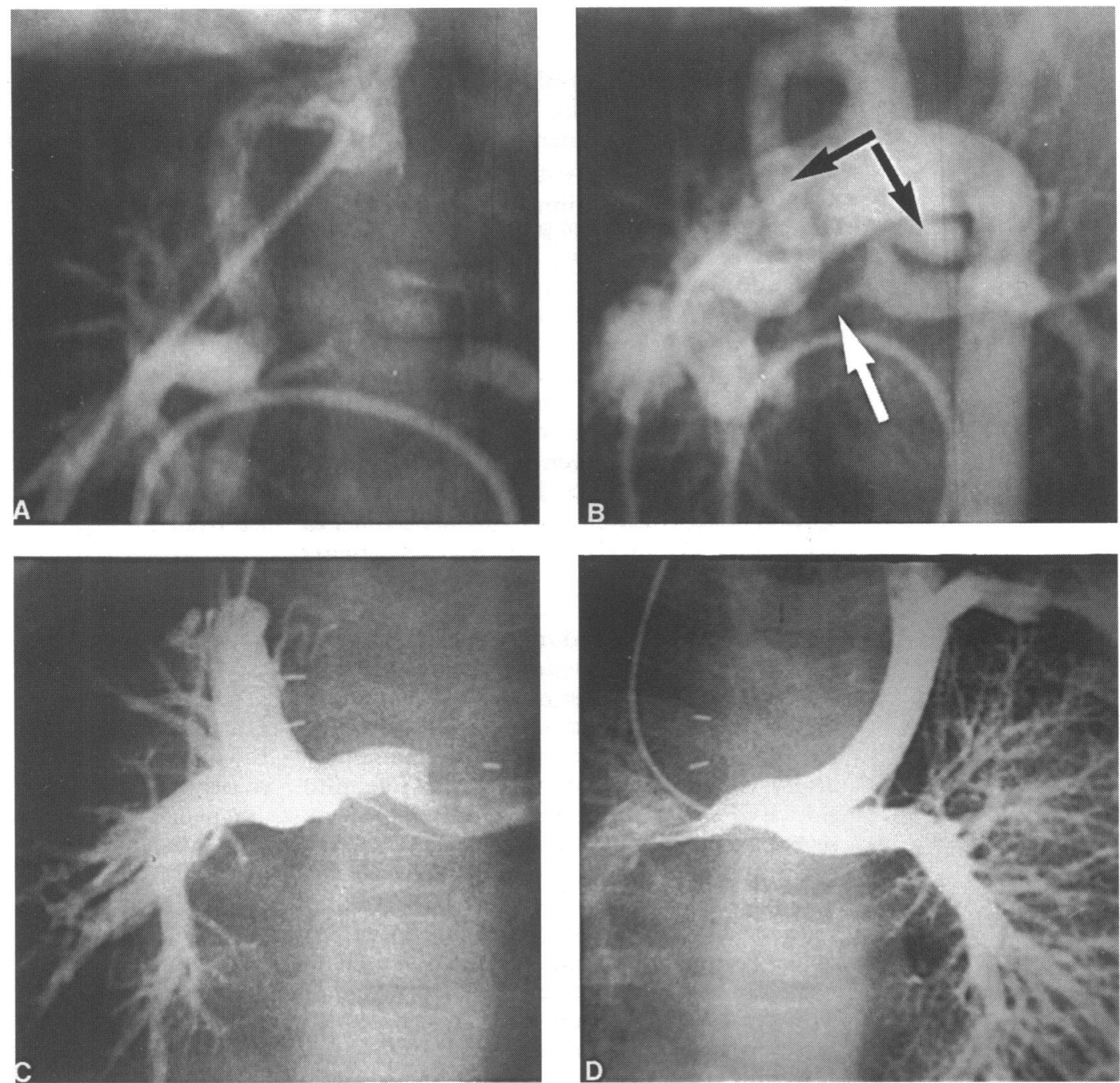

1), there was intermittent severe hypoxaemia (saturations $60-80 \%$ ), although the arterial duct appeared patent on echocardiogram. In the other (case 2), there was a restrictive interatrial communication and balloon atrial sep-

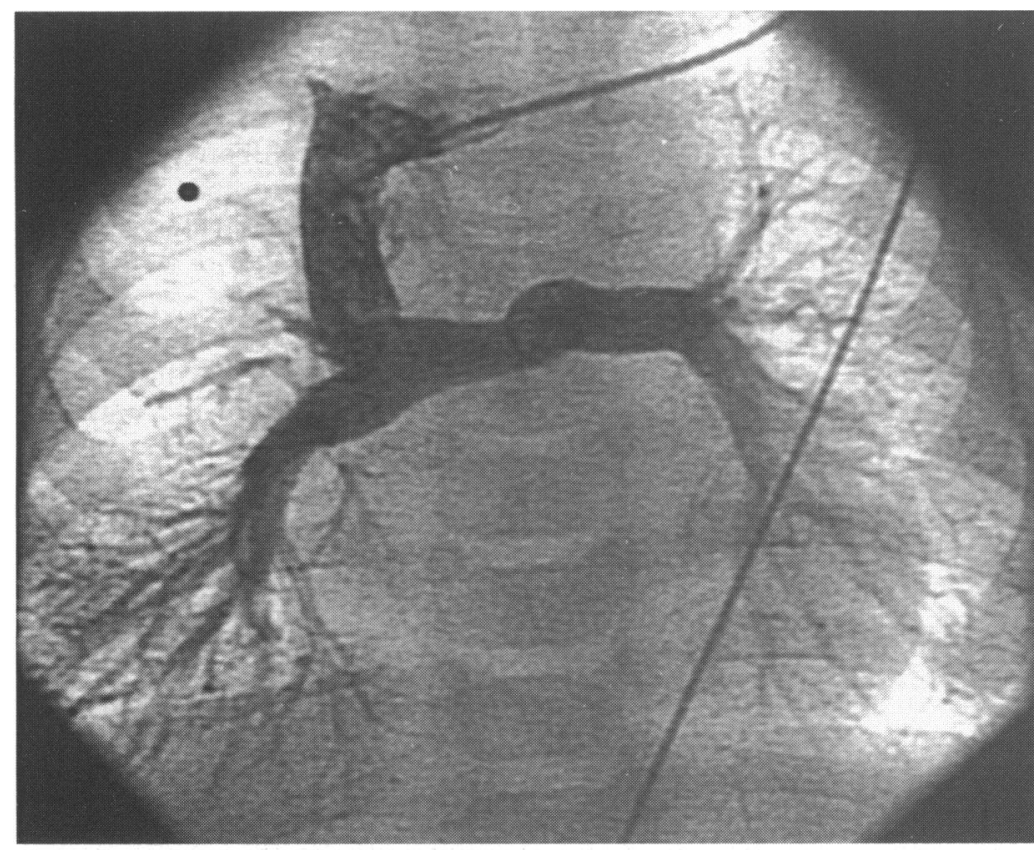

Figure 2 Anteroposterior angiogram showing bidirectional superior cavopulmonary anastomosis performed via a right thoracotomy (case 2).

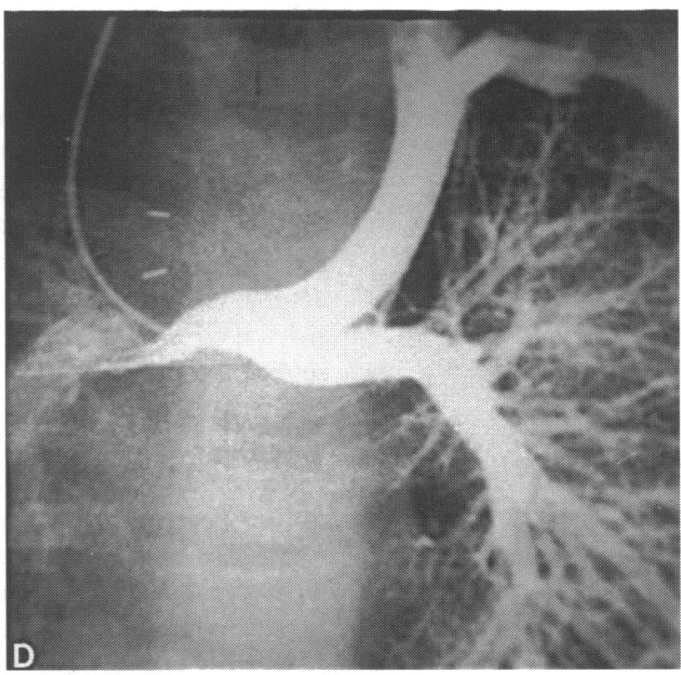

tostomy was performed at the age of $14 \mathrm{~d}$.

Two patients had double inlet left ventricle. In one (case 3 ), this was associated with discordant ventriculoarterial connection and unobstructed pulmonary blood flow. In the other (case 4), there was a single outlet (aorta arising from the right ventricle) with pulmonary atresia. Pulmonary arterial supply was from bilateral arterial ducts and the proximal right pulmonary artery was severely hypoplastic (fig 1). The innominate vein had a subaortic course. This patient received intravenous prostaglandin E1 infusion up until the time of surgery.

The indication for surgical intervention was progressive cyanosis in two patients (cases 2 and 4 ; systemic saturations $65 \%$ and $75 \%$ respectively), and intermittent cyanosis (saturations down to $60 \%$ ) in one (case 1 ). In the remaining infant (case 3) with unobstructed pulmonary blood flow, surgery was required to control congestive heart failure and to protect the pulmonary vascular bed.

\section{OPERATIVE TECHNIQUE}

In the two patients with tricuspid atresia, BCPA was performed through a right thoracotomy without the use of cardiopulmonary bypass. ${ }^{1}$ A side to side anastomosis was fashioned between the superior caval vein and the right pulmonary artery (fig 2 ). In one case a side biting vascular clamp was used to allow 
continued flow to the right atrium while the anastomosis was performed. In the youngest infant, the superior caval vein was of insufficient size to allow this manoeuvre and its superior portion was therefore cross-clamped. The superior caval pressure was continuously monitored and did not exceed $25 \mathrm{~mm} \mathrm{Hg}$. The alternate sources of pulmonary blood flow (by the main pulmonary artery in both cases, with additional flow from a patent ductus arteriosus in one) were left patent in both cases.

Both patients with double inlet left ventricles underwent surgical correction through a median sternotomy on cardiopulmonary bypass with deep hypothermic circulatory arrest. In case 3 the ventricular septal defect was noted to be elliptical in nature with a cross sectional area significantly smaller than the aortic root size. It was therefore felt that early relief of subaortic stenosis was indicated, and that this would be best achieved by a modified arterial switch procedure. The main pulmonary artery was divided and the proximal portion of the distal segment was oversewn. The aorta and coronary arteries were transferred to the proximal stump of the pulmonary artery. The aortic valve was closed. An end to side BCPA was performed. In case 4 , with severe proximal pulmonary arterial hypoplasia, both arterial ducts were divided. The central hypoplastic portion of the pulmonary arteries was opened longitudinally and the distal part of the subaortic innominate vein was used to reconstruct the central hypoplastic segment. This preserved flow from the innominate vein direct to the central pulmonary arteries (fig 1). A bidirectional cavopulmonary anastomosis was fashioned between the posterior wall of the superior caval vein and the anterior aspect of the right pulmonary artery. The cava was ligated below this site.

Temporary prostacyclin infusion was used in three patients (case 1,3 , and 4 ) in the immediate postoperative period.

\section{Results}

There were no perioperative deaths. Case 1 (with tricuspid atresia and postoperative competitive pulmonary blood flow through both the pulmonary valve and patent ductus arteriosus) developed severe superior vena cava syndrome shortly after bidirectional cavopulmonary anastomosis, with profound upper body oedema. Ligation of the ductus arteriosus was performed $96 \mathrm{~h}$ after the initial operation. Chronic pleuropericardial effusions contributed to a prolonged intensive care unit (19 d) and hospital stay (38 d). Cases 2-4 had a smoother postoperative course with extubation at 5,7 , and $48 \mathrm{~h}$ respectively. Case 3 also developed prolonged postoperative effusions requiring drainage.

Three of the patients (cases 1, 3, and 4) had significant systemic arterial desaturation (< $70 \%$ ) during the first $24 \mathrm{~h}$ after surgery. In case 4 , saturations fell as low as $40 \%$ in the first few hours postoperatively, although without the development of acidosis. At hospital discharge, systemic saturations of the four patients ranged from $72 \%$ to $85 \%$ and at follow up these rose to $80-84 \%$. All patients underwent cardiac catheterisation postoperatively (4-14 months). The mean pulmonary artery pressure was $12 \mathrm{~mm} \mathrm{Hg}(10-16)$, no patient having a gradient between the pulmonary artery and superior caval vein. No pulmonary arteriovenous malformations were identified. Pulmonary arterial growth was observed in all cases. Mean ratio of right and left pulmonary artery diameters to descending aorta (McGoon ratio) in the three patients with pulmonary outflow obstruction rose from 1.5 preoperatively to 1.8 postoperatively. In case 4 (with unobstructed pulmonary blood flow preoperatively) pulmonary arterial growth was seen after BCPA, but the McGoon ratio fell from $3 \cdot 0$ to $2 \cdot 3$.

At the latest follow up, 14-48 months postoperatively, all patients were well and none were taking medication. None had effusions or upper body oedema.

\section{Discussion}

Bidirectional superior cavopulmonary anastomosis is being used with increasing frequency as a palliative procedure for patients with complex congenital heart disease. ${ }^{1-5}$ This procedure offers several potential advantages over the use of systemic to pulmonary shunts. In particular, it avoids pulmonary arterial distortion and also the additional volume load on the systemic ventricle created by the use of systemic to pulmonary shunts. Both these complications are important risk factors for subsequent Fontan repair. ${ }^{8-10}$ In addition, bidirectional cavopulmonary anastomosis is a more logical strategy as it represents an evolution of the patients' anatomy towards the final Fontan circulation.

The results of bidirectional cavopulmonary anastomosis in older children have been very encouraging, with low operative mortality and excellent palliation being achieved in most patients. ${ }^{1245}$ The logical extension of these results is the application of bidirectional cavopulmonary anastomosis to younger patients, including infants. Albanese and colleagues $^{3}$ reported the results of BCPA in 27 children less than 2 years of age. The youngest was 2 months old, but the majority were above 1 year of age (mean 14.2 months). Overall, the results were satisfactory, though four patients died perioperatively $(15 \%)$. This rather high early mortality probably reflects the complex anatomy rather than the young age at operation. Three of the deaths were in patients with atrial isomerism associated with severe common atrioventricular valve regurgitation or pulmonary venous obstruction. Chang and colleagues $^{7}$ reviewed the results of BCPA in a group of 17 infants, $4 \cdot 2$ to 6.6 months of age. There was only one perioperative death and palliation was generally excellent. In both these series, the majority of patients had undergone previous palliation, mostly with systemic to pulmonary shunts. None of the patients studied was less than 2 months of age at BCPA. Therefore, these studies do not 
address the issue of whether BCPA can be used as a primary palliation for complex forms of congenital heart disease in the first few weeks of life.

Reluctance to use BCPA in neonates and very young infants comes from the unfavourable experience with the classical Glenn anastomosis in infancy. ${ }^{11} 12$ Of particular concern is the increased pulmonary vascular resistance present in the newborn period and the potential for postoperative pulmonary vascular reactivity in young infants, even if pulmonary vascular resistance is normal before surgery. The latter is especially relevant in cases where the pulmonary vascular bed is unprotected and pulmonary blood flow is excessive.

Because of the potential advantages of BCPA as a primary palliation for complex forms of congenital heart disease, we have explored the feasibility of using this technique in infants younger than 8 weeks of age. All four of our patients are alive and well without medication. Systemic oxygen saturations at follow up range from $80 \%$ to $87 \%$; these values do not differ from those of our older patients who have undergone BCPA. ${ }^{13}$ Angiography has also confirmed pulmonary arterial growth in all patients. This is an important observation, since no serial data are currently available to show that BCPA in infancy will result in satisfactory pulmonary arterial growth.

Although these results are encouraging, caution is warranted. The postoperative course of this small group was more complicated than that seen with BCPA in older infants and children. We postulated that these patients would tolerate the procedure, providing low pulmonary vascular resistance could be maintained postoperatively. This may be an unrealistic expectation, particularly when profound hypothermia and circulatory arrest are used as additional procedures concomitant with BCPA. Case 3 is therefore of particular interest. This is the first time we have performed a BCPA in the setting of systolic pulmonary artery pressures at systemic level. Surgery was indicated for control of congestive cardiac failure and protection of the pulmonary vascular bed, rather than for cyanosis. Preoperatively there was torrential pulmonary blood flow and very low pulmonary vascular resistance. The ventricular septal defect was restrictive at presentation and a modified arterial switch procedure with BCPA avoided the inevitable sequelae of subaortic stenosis that would have followed banding of the pulmonary trunk. ${ }^{1415}$ Whether such an approach is prudent remains to be determined. Most cardiologists would not, at present, consider BCPA in the setting of pulmonary arterial pressure at systemic level, no matter how low the preoperative pulmonary vascular resistance. As our ability to manipulate pulmonary vascular resistance in the postoperative period improves, ${ }^{16}$ consideration should perhaps be given to this strategy in selected patients.

Case 1 also warrants specific comment. In retrospect, lability of both the pulmonary vascular bed and right ventricular outflow obstruction, rather than constriction of the ductus arteriosus, were probably responsible for the marked swings in arterial saturations preoperatively. Although we have recently shown that competitive sources of pulmonary blood flow are usually very well tolerated following bidirectional cavopulmonary anastomosis $^{13}$ this patient did not tolerate the presence of what proved to be a large patent ductus and antegrade flow from the right ventricle. It would, perhaps, have been more appropriate to avoid BCPA or to have performed it through a median sternotomy with ligation of the ductus arteriosus or pulmonary trunk.

Although the postoperative course was more difficult than that commonly seen in older children, we have shown that it is feasible to perform bidirectional superior cavopulmonary anastomosis as primary palliation in young infants less than 8 weeks of age. While we would not yet advocate this as a standard approach in this age group, we do believe that this warrants further exploration. It may be prudent, in the first instance, to expand our experience with cyanotic infants with low pulmonary blood flow and pulmonary vascular resistance, who do not require concomitant additional surgical procedures. In this way it will be possible to examine the postoperative course of BCPA in very young infants without the confounding effects of additional surgical procedures.

1 Salmon AP, Sethia B, Silove ED, Goh D, Mitchell I, Alton $\mathrm{H}$, et al. Cavopulmonary anastomosis as long-term palliation for patients with tricuspid atresia. Eur f Cardiothorac Surg 1989;3:494-8.

2 Bridges ND, Jonas RA, Mayer JE, Flanagan MF, Keane JF, Castaneda AR. Bidirectional cavopulmonary anastomosis as interim palliation for high risk Fontan candidates: early results. Circulation 1993;88:2128-38.

3 Albanese SB Carotti A Di Donato RM, Mazzera E Troconis CJ, Giannico S, et al. Bidirectional cavopulmonary anastomosis in patients under two years of age. $\mathcal{F}$ Thorac Cardiovasc Surg 1992;104:904-9.

4 Hawkins JA, Shaddy RE, Day RW, Sturtevant JE, Orsmond GS, McGough EC. Mid-term results after bidirectional cavopulmonary shunts. Ann Thorac Surg 1993;56:833-7.

5 Pridjian AK, Mendelsohn AM, Lupinetti FM, Beekman RH, Dick M, Serwer G, et al. Usefulness of the bidirectional Glenn procedure as staged reconstruction for the functional single ventricle. Am F Cardiol 1993;71:959-62.

6 Lamberti JJ, Spicer RL, Waldman JD, Grehl TM, Thompson D, George L, et al. The bidirectional cavopulmonary shunt. F Thorac Cardiovasc Surg 1990;100:22-30.

Chang AC Wessel DI Wessel DL, Jonas RA, et al. Early bidirectional cavopulmonary shunt in young infants. Postoperative

8 Mietus-Snyder M, Lang P, Mayer JE, Jones RA, Castaneda AR, Lock JE. Childhood systemic-pulmonary shunts: AR, Lock JE. Childhood systemic-pulmonary shunts: subsequent suitability

9 Kirklin JK, Blackstone EH, Kirklin JW, Pacifico AD, Bargeron LM Sr. The Fontan operation: ventricular hypertrophy, age and date of operation as risk factors. $\mathcal{F}$ Thorac Cardiovasc Surg 1986;92:1049-64.

10 Seliem M, Muster AJ, Paul MH, Benson DW. Relation between preoperative left ventricular muscle mass and outcome of the Fontan procedure in patients with tricuspid atresia. $\mathcal{F}$ Am Coll Cardiol 1989;14:750-5.

11 Glenn WWL. Superior vena cava-pulmonary artery shunt. Ann Thorac Surg 1989;47:62-4

12 Kopf GS, Laks H, Stansel HC, Hellenbrand WE, Kleinman CS, Talner NS. Thirty-year follow-up of superior vena cava-pulmonary artery (Glenn) shunts. f Thorac Cardiovasc Surg 1990;100:662-71.

13 Slavik Z, Salmon AP, LeBlanc JG, Horvath P, Hucin B, Skovranek $\mathrm{J}$, et al. The influence of competitive pulmovrary blood flow on the bidirectional superior cavopulmonary blood fow on the bidirectional superior cavopulf 1994;71:S-8.

14 Freedom RM, Benson LN, Smallhorn JF, Williams WG, Trusler GA, Rowe RD. Subaortic stenosis, the univentricular heart, and banding of the pulmonary artery: an 
analysis of the courses of 43 patients with univentricular heart palliated by pulmonary artery banding. Circulation 1986;73:758-64.

15 Franklin RC, Sullivan ID, Anderson RH, Shinebourne EA, Deanfield JE. Is banding of the pulmonary trunk obsolete for infants with tricuspid atresia and double inlet ventricle with a discordant ventriculo-arterial connection? Role of aortic arch obstruction and subaortic stenosis. $\mathcal{F} \mathrm{Am}$ Coll Cardiol 1990;16:1455-64.

16 Wessel DL, Adatia I, Giglia TM, Thompson JE, Kulik TJ Use of inhaled nitric oxide and acetylcholine in the evaluation of pulmonary hypertension and endothelial function after cardiopulmonary bypass. Circulation 1993;88: $2128-38$.

\title{
SHORT CASES IN CARDIOLOGY
}

\section{Large left ventricular thrombus in a patient with Friedreich's ataxia}

\author{
K Reynen, D Claus, A Bornemann
}

Department of Internal Medicine II, University of Erlangen-Nürnberg, Erlangen, Germany K Reynen

Department of Neurology, University of Erlangen-Nürnberg, Erlangen, Germany D Claus

Department of Pathology, University of Erlangen-Nürnberg, Erlangen, Germany

A Bornemann

Correspondence to: Dr K Reynen, Departmen of Internal Medicine II, University of ErlangenNürnberg, Östliche Stadtmauerstrasse 29, D-91054 Erlangen Germany.

Accepted for publication 17 July 1995

Large apical thrombus (arrow) in the left ventricle, which was of normal size, visualised by cross sectional echocardiography (transthoracic approach, apical view). $L V$, left ventricle; $R V$, right ventricle; $L A$ left atrium; $R A$, right atrium.
A 25 year old woman was admitted to the hospital because of fatigue, palpitation, and dyspnoea on minor exertion. Nineteen years before, Friedreich's ataxia had been diagnosed. On physical examination, the patient presented characteristic findings of Friedreich's ataxia, including marked ataxia, dysarthria, generalised weakness, severe scoliosis, and cavus deformity of the foot. No heart murmur was audible. The electrocardiogram showed atrial flutter with 2:1 atrioventricular conduction; the QRS rate was $170 / \mathrm{min}$. Echocardiography revealed biventricular hypertrophy with left ventricular wall thickness of $13 \mathrm{~mm}$, severe global hypokinesis of a left ventricle of normal size, and a large apical thrombus $(3.5 \times 2.5 \mathrm{~cm})$ (figure).

About 20 hours after the echocardiographic examination, the patient suddenly lost consciousness; she was intubated because of respiratory insufficiency. Although pulses of the carotid arteries were strongly palpable, pulses at all four extremities were not. Thrombus embolisation was therefore suspected, and confirmed by echocardiography. The neuro-

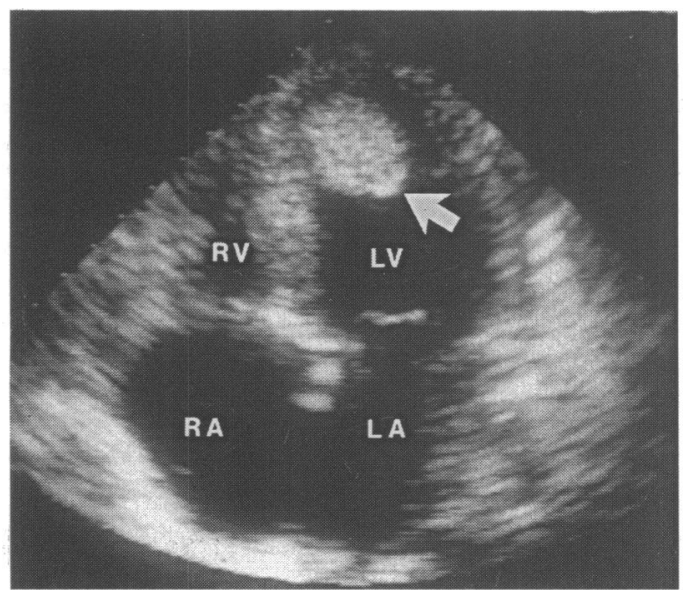

logical disorder and the apparent cerebrovascular involvement ruled out vascular surgical intervention.

At necropsy residual thrombotic material was present in the apex of the left ventricle. Occlusive thrombotic material was found in the left internal carotid artery, the left subclavian and right brachial artery, and the aortic bifurcation

Although Friedreich's ataxia is primarily an inherited progressive neurological disease, heart failure is the most common cause of death in these patients. ${ }^{1}$ Concentric or, less frequently, asymmetrical left ventricular wall thickening may readily be detected by echocardiography: rarely, a picture of dilated cardiomyopathy is found. ${ }^{23}$ Echocardiography also allows assessment of systolic and diastolic ventricular function. ${ }^{3}$ Increasing physical immobility can mask myocardial insufficiency for a long time. Atrial arrhythmias raise suspicions of left ventricular dysfunction and indicate a poor prognosis. ${ }^{13}$ Occasional peripheral emboli resulting from mural thrombi or, more usually, from atrial thrombi in cases of atria fibrillation may occur in Friedreich's ataxia The thrombus was exceptionally large in this case and there was massive lethal embolisation. Anticoagulation should be considered in patients with Friedreich's ataxia and impaired ventricular wall motion or atrial fibrillation.

Hewer RL. Study of fatal cases of Friedreich's ataxia. BMF 1968;iii:649-52.

Child JS, Perloff JK, Bach PM, Wolfe AD, Perlman S, Kark RAP. Cardiac involvement in Friedreich's ataxia: clinical study of 75 patients. 7 Am Coll Cardiol 1986; 7:1370-8

3 Alboliras ET, Shub C, Gomez MR, Edwards WD, Hagler DJ, Reeder GS, et al. Spectrum of cardiac involvement in Friedreich's ataxia: clinical, electrocardiographic and echocardiographic observations. Am $\mathcal{f}$ Cardiol 1986; 58:518-24. 